\title{
Prosthetic mitral valve thrombosis in a known case of rheumatic heart disease at 37 weeks pregnancy: a case report
}

\author{
Kirty Nahar ${ }^{1 *}$, Nikita Nahar ${ }^{2}$ \\ ${ }^{1}$ Department of obstetrics and Gynaecology, Apollo Hospitals International Ltd., Ahmedabad, Gujarat, India \\ ${ }^{2}$ Smt NHL Municipal Medical College, Ahmedabad, Gujarat, India
}

Received: 25 June 2021

Accepted: 20 July 2021

*Correspondence:

Dr. Kirty Nahar,

E-mail: naharkirty@yahoo.co.in

Copyright: $\odot$ the author(s), publisher and licensee Medip Academy. This is an open-access article distributed under the terms of the Creative Commons Attribution Non-Commercial License, which permits unrestricted non-commercial use, distribution, and reproduction in any medium, provided the original work is properly cited.

\begin{abstract}
Pregnancy with prosthetic valve is a challenging situation since this is a hypercoagulable state and maintenance of anticoagulation for prosthetic valves becomes difficult due to the teratogenic effects and altered pharmacokinetics of anticoagulant drugs. Despite adequate anticoagulation, the incidence of prosthetic valve thrombosis has been estimated as $4 \%$ to $14 \%$ during pregnancy. Management decisions for this life-threatening complication are complex. Open-heart surgery has a very high risk of maternal mortality and fetal loss, especially in early pregnancy. Furthermore, bleeding and embolic risks associated with thrombolytic agents, the limited efficacy of thrombolysis in certain subgroups, and a lack of experience in the setting of pregnancy raise important concerns. Mrs. X, a 36-year-old, gravida 3, para1+1 with 37 weeks pregnancy presented at Apollo hospitals, Ahmedabad in emergency department with complaints of severe dry cough and breathlessness for 24 hours. On through workup, she was diagnosed as mitral valve thrombosis in a known case of rheumatic heart disease post mitral valve replacement at 37 weeks pregnancy with late onset fetal growth restriction. After multi-speciality consultation she underwent thrombolytic therapy followed by high-risk emergency caesarean section. She delivered healthy male child, weight $2.21 \mathrm{~kg}$ and was discharged on $4^{\text {th }}$ post-op day. Management of pregnant patients with mechanical valves is complex, especially when valve thrombosis and other complications occur. Multidisciplinary approach is essential and, in this case, led to successful maternal and foetal outcome.
\end{abstract}

Keywords: Caesarean, Prosthetic valve thrombosis, Pregnancy, Anticoagulation, Thrombolysis, Echocardiography

\section{INTRODUCTION}

Rheumatic heart disease (RHD) has a high prevalence of $0.9 / 1000$ in India among school children. ${ }^{1}$ Young females having undergone valve replacement when become pregnant face an uphill task of maintaining anticoagulation required for prosthetic heart valve (PHV).

Pregnancy being a hypercoagulable state, teratogenic effects of anticoagulant drugs and altered pharmacokinetics increase predisposition for prosthetic heart valve (PHV) thrombosis, which, in the presence of physiological changes of pregnancy, may lead to life threatening situations, followed by a dilemma regarding the timing of delivery, replacement of the thrombosed $\mathrm{PHV}$ and risk of post-partum haemorrhage (PPH).

The risk of complications in pregnancy is high in patients with mechanical prosthetic heart valves. Up to $42 \%$ of these pregnant patients experience serious adverse events. ${ }^{2}$ Thrombotic and bleeding complications vary depending upon selected anticoagulation regime but remain high.,3 While warfarin may carry a lower risk of valve thrombosis, warfarin is teratogenic in first trimester and is associated with increased foetal loss throughout the pregnancy.

Guidelines recommend the use of warfarin up to the $36^{\text {th }}$ week of pregnancy, excluding the period between the $6^{\text {th }}$ and $12^{\text {th }}$ weeks. On the other hand, daily warfarin 
treatment at a dose of $5 \mathrm{mg}$ or lower reduces the risk of valve thrombosis in the mother to a lower degree, in the absence of fetal malformation risk. ${ }^{4,5}$ Though heparin use is not associated with the risk of embryopathy, the incidence of thromboembolic complications may be more than that observed with warfarin. Heparin does not cross the placenta but is associated with increased maternal morbidity and mortality. $2,3,6,7$

Despite adequate anticoagulation, the incidence of PVT has been estimated as $4 \%$ to $14 \%$ during pregnancy. ${ }^{8}$ Prosthetic valve thrombosis occurring during pregnancy requires urgent therapy including fibrinolytic therapy, valve replacement, and surgical thrombectomy due to high mortality. ${ }^{9}$ Although surgery has traditionally been the standard procedure for treatment of PVT, fibrinolytic therapy may be used as first-line therapy according to data from recent reports. ${ }^{10,11}$ Data about the fibrinolytic therapy is scarce and controversial in the setting of pregnancies complicated with PVT.

Here we report an interesting case of of mitral valve thrombosis in a known case of rheumatic heart disease, status post mitral valve replacement in a gravida 3, para $1+1,37$ weeks pregnancy.

\section{CASE REPORT}

Mrs. X, a 36-year-old, gravida 3, para1+1, 9 months amenorrhoea, LMP-24.04.20, EDD-31.01.21 presented at Apollo hospitals international Ltd, Gandhinagar in emergency department at 12.30 am on 08.01.21 with complaints of severe dry cough and breathlessness since $11 \mathrm{pm}$ on 06.01.21. She had breathlessness on routine work for 3 days. She was a known case of rheumatic heart disease with mitral valve replacement 10 years back at a private hospital, Rajkot. In initial 3 months of pregnancy patient was on inj. enoxaparine sodium $0.6 \mathrm{ml}$ subcutaneously twice daily then shifted to oral anticoagulants tab acitrom $3 \mathrm{mg}$ orally and continued till 20.12.2. Thereafter she was restarted on inj. enoxaparine sodium $0.6 \mathrm{ml}$ subcutaneously twice daily till date. She was also on tab digoxin $0.25 \mathrm{mg}, 5$ days a week and tab metoprolol XL $100 \mathrm{mg}$ daily.

\section{Obstetric history}

$1^{\text {st }}$ full term normal vaginal delivery, female child-10 years, alive and healthy. $2^{\text {nd }}$ pre term vaginal delivery at 6 months, female child, baby died just after delivery, 4 years back. Last delivery-4 years.

\section{Past history}

History of mitral valve thrombosis in past in February 2019 was managed medically.

\section{Family history}

Not contributory.

\section{On examination}

Patient was thin built, weight-52 kg, face-puffy, pulse rate$100 / \mathrm{min}, \mathrm{BP}-116 / 76 \mathrm{mmHg}$, temperature- $98 \mathrm{~F}, \mathrm{SPO}_{2-}$ $91 \%$ on oxygen 6 litre/min, CVS-dull prosthetic closing click, mid diastolic apical murmur +, RS-RR: 30/min, bilateral air entry present, tachypnea + wheeze present + .

\section{Per abdomen}

Uterus 34 weeks, floating head, fetal heart sound + regular, uterus relaxed.

\section{Bimanual examination}

Cervical OS closed.

\section{Investigations}

On 08/01/21, CBC: HB-12.7 gm\%, WBC-17,072/cumm. DC: N-81\%, L-15\%, M-02\%, E-02\%, B-0\%. Platelets3,07,000/cumm, PT(T)-13.6, (C)-12.3, INR-1.12, D. Dimer-1.23 mcg/ml, S. urea- $25 \mathrm{mg} / \mathrm{dl}, \mathrm{S}$. creatinine- 0.62 $\mathrm{mg} / \mathrm{dl}$, total bilirubin- $0.85 \mathrm{mg} / \mathrm{dl}$, direct- $0.353 \mathrm{mg} / \mathrm{dl}$, indirect-0.492 mg/dl, blood group-A positive, COVID-19 RTPCR-negative, HIV and HBsAg-non reactive.

Electrocardiography (08.01.21) showed sinus tachycardia, ventricular heart rate $150 / \mathrm{min}$.

2D echocardiography (08.01.21) showed echogenic mass in prosthetic mitral valve suggestive of thrombus with reduced mobility of valve, peak gradient across mitral valve- 35, LVEF: 55-60\%, dilated left atrium, right atrium and right ventricle, moderate $\mathrm{AR}$, moderate TR. Mild PAH, RVSP:40 mmHg.

Ultrasound obstetrics III trimester scan with doppler study (08.01.21) showed single live intrauterine fetus, gestational age 33 weeks, 1 day, placenta posterior grade II, fetal weight $2078 \pm 311$ gm, Doppler study: umbilical artery PI-1.32 above $95^{\text {th }}$ percentile, middle cerebral artery PI-1.4 below $5^{\text {th }}$ percentile, cerebro placental ratio- 0.92 , both uterine artery doppler showed high resistance waveform with mean PI of 1.3 , above $95^{\text {th }}$ percentile, suggestive of late onset foetal growth restriction.

Clinical diagnosis of gravida 3, para1+1, 37 weeks pregnancy with late onset fetal growth restriction with prosthetic mitral valve thrombosis in a known case of rheumatic heart disease was made.

After multidisciplinary evaluation of available treatment options, as the patient was of New York heart association (NYHA) functional class II, decision was taken for thrombolysis and hence patient shifted to Medical intensive care unit. Casarean section was planned after thrombolysis when the patient's clinical condition stabilizes, hence inj. enoxaparine was stopped. She was managed with inj. zostum $1.5 \mathrm{gm}$ (sulbactum and 
cefoperazone) 12 hourly and inj gentamycin $1.2 \mathrm{gm} \mathrm{I} / \mathrm{V} 6$ houly, intravenous fluids, oxygen by mask at 4 litres $/ \mathrm{min}$., inj. furosemide $10 \mathrm{mg} \mathrm{I} / \mathrm{V}$ in morning and $5 \mathrm{mg} \mathrm{I} / \mathrm{V}$ in afternoon, tab metoprolol XL $100 \mathrm{mg}$ twice daily, tab digoxin $0.25 \mathrm{mg}$ once a day was continued. Thrombolysis was done with inj streptokinase-1.5 lakh international units bolus followed by inj. streptokinase-1 lakh international units I/V given over 12 hours at the rate of $4 \mathrm{ml} /$ hour.

After completion of thrombolysis on 09.01 .21 at $1.15 \mathrm{pm}$, CTG was done, it was reactive and reassuring. CTG repeated after 4 hours at $5.20 \mathrm{pm}$ and it was non reassuring showing decelerations and decreased baseline variability. In view of suspected foetal distress, decision was taken for high-risk lower segment caesarean section. Patient was assessed by PT, aPTT and after normal findings patient was taken for surgery. 4 units of FFP, 3 units of cryoprecipitate were transfused prior to surgery.

Patient underwent high-risk emergency lower segment Csection under general anesthesia on 08.01.21, male child, weight $2.21 \mathrm{~kg}$ delivered at 8:21 pm (Figure 1 and 2).

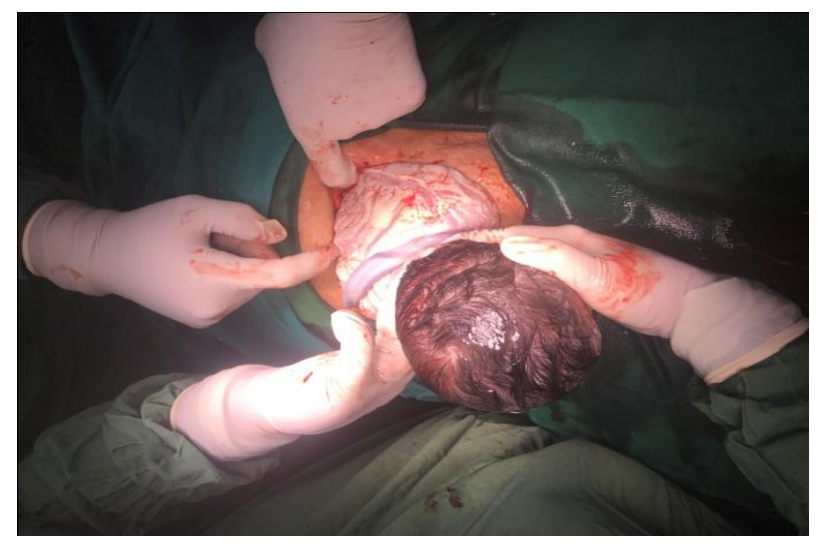

Figure 1: Caesarean section delivery of baby.

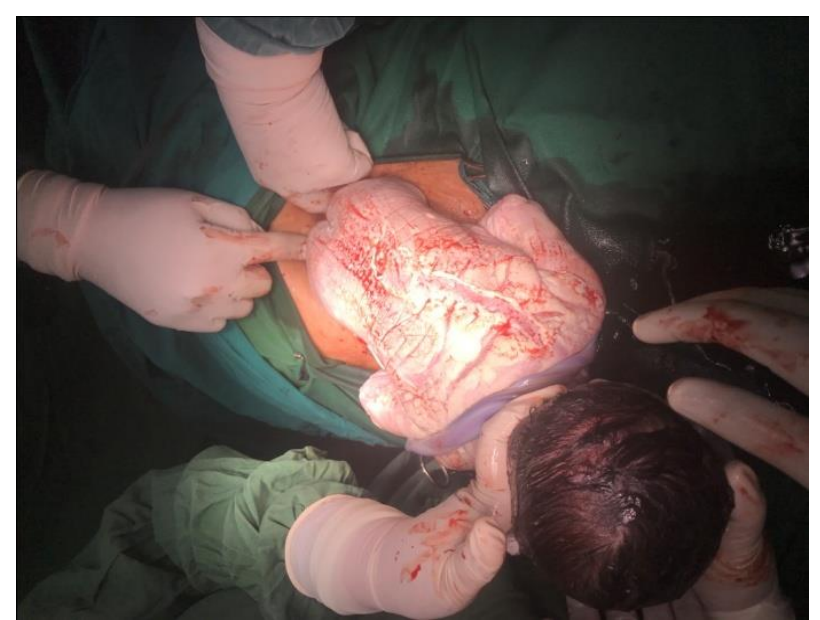

Figure 2: Caesarean section-baby delivered as vertex.

Oxytocin infusion (10 units/hour) was started postdelivery to improve uterine contraction and facilitate placental delivery. Uterine contraction was assured and abdomen was closed with meticulous haemostasis. The 2 units of packed cell volume were given intraoperatively and post-operatively (Figure 3 and 4).

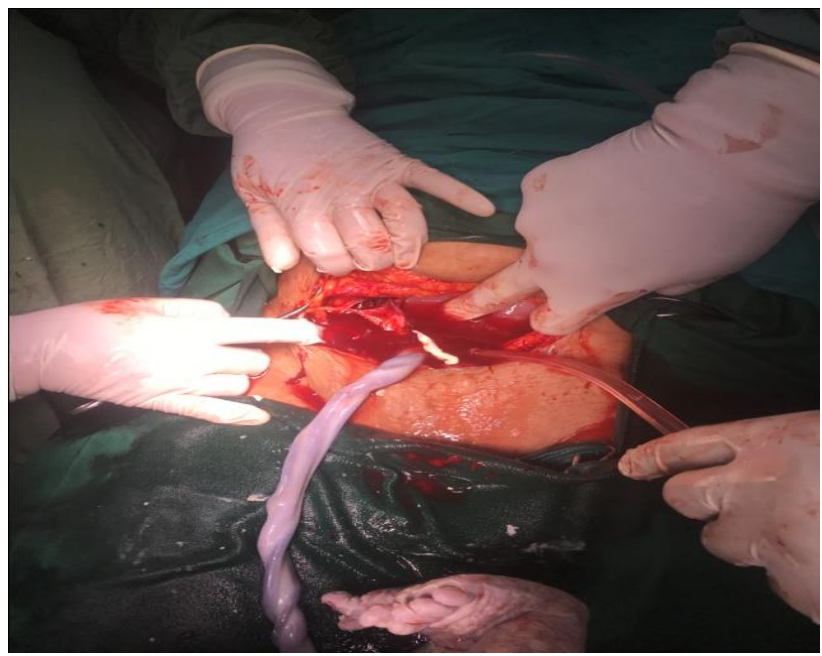

Figure 3: Cord clamped and cut, placenta within uterus. No active bleeding.

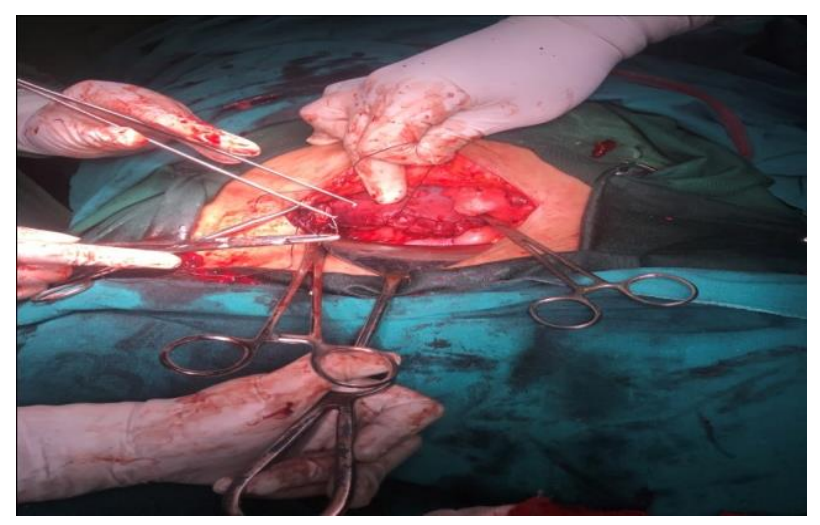

Figure 4: Uterus well contracted. Suturing of uterus achieving proper haemostasis.

Post operatively she was again shifted to medical intensive care unit for further care and management. Complete blood count on 09.01.21 showed hemoglobin $10.2 \mathrm{gm} \%$, WBC-17,930/ cu.mm, DC: N-93\%, L-04\%, M-02\%, E$01 \%$, B-0\%, platelets-3,66,000/cumm.

The 2-dimensional echocardiography on 09.01.21, 10.30 am showed marginal improvement in opening of mitral Valve post thrombolysis, peak gradient across mitral valve -20 , LVEF: $60 \%$, trivial AR, trivial TR, trivial MR.

LMWH (inj. enoxaparine) was restarted after 12 hours of surgery at the dose of $0.6 \mathrm{ml}$ twice daily. Patient was managed medically with antibiotics, antacids, analgesics, intravenous fluids and other supportive care. Postoperatively patient recovered well.

Dressing was done on $4^{\text {th }}$ post-operative day, wound healthy. Patient was bridged onto oral anticoagulation, 
counseled on contraception and was discharged in stable haemodynamic condition on 11.01.21 with healthy baby. She was advised to come for follow up after 7 days with $\mathrm{CBC}, \mathrm{PT}$, INR and renal function test.

On follow up after 2 weeks, patient was healthy taking her regular cardiac medications. There was superficial gaping of wound on left angle of stitch line with serosanguious discharge for which alternate day dressing was done and wound healed well.

At 4 months follow up, patient had no complaints. Her child was healthy, growing well, weight $4.2 \mathrm{~kg}$ and was taking breast feed properly.

\section{DISCUSSION}

Pregnancy in a patient with a mechanical prosthesis is associated with maternal mortality between $2 \%$ and $15 \%$, mainly due to valve thrombosis while on heparin therapy. ${ }^{12}$

PHV thrombosis leads to a state similar to untreated mitral stenosis, with clinical features depending on the degree of thrombosis and narrowing of orifice. Physiologically, in pregnancy, an increased heart rate $(25 \%)$, blood volume (45\%) and cardiac output (50\%) significantly increase the gradient across the stenosed orifice and cause pulmonary congestion, due to high left atrial pressure, and low $\mathrm{CO}$, due to decreased forward flow into left ventricle, and decreased venous return due to aortocaval compression. ${ }^{13}$

The management of pregnant patients with mechanical prosthetic valves involves several complex issues. Vitamin $\mathrm{K}$ antagonists between the sixth and the twelfth weeks have been associated with an increased risk; $0.6 \%$ and $10 \%$ for embryopathic effects (because the drugs cross the placenta) or early abortion, and the risk is dose-related (it is relatively low in patients taking $\leq 5 \mathrm{mg}$ warfarin per day). ${ }^{14-16}$ Delivery without prior suspension of oral anticoagulation (OAC) is associated with an increased risk of bleeding in the neonate. ${ }^{14}$

UFH and LMWH do not cross the placenta and there is thus no risk of embryopathy; they may be used during pregnancy in patients with mechanical prosthetic valves, especially during the first 12 weeks of gestation. The superiority of either UFH or LMWH in the first trimester is unproven. Long-term heparin therapy is difficult to manage and the incidence of prosthetic thrombosis appears to be considerably higher with heparin than with vitamin $\mathrm{K}$ antagonists, even when using adjusted doses of the former. ${ }^{12} \mathrm{LMWH}$ has the advantage of providing a more stable antithrombotic effect; nevertheless, experience with administration during pregnancy in patients with mechanical heart valves is limited, and weekly monitoring of anti-factor Xa levels is required to adjust the dose in order to achieve therapeutic levels of anticoagulation. ${ }^{14}$ The efficacy of LMWH during pregnancy has been demonstrated in the prevention and treatment of venous thromboembolism.
For the first trimester in patients with mechanical heart valves, discontinuation of OAC between weeks 6 and 12 and a switch to adjusted-dose UFH (aPTT $\geq 2$ times control; in high-risk patients applied as intravenous infusion) or LMWH (twice daily with dose adjustment according to body weight and to target anti-Xa level of 0.8 1.2 $\mathrm{U} / \mathrm{ml}$ at 4-6 hours post-dose) should be considered in patients with a daily dose requirement of $>5 \mathrm{mg}$ for warfarin or $>2 \mathrm{mg}$ for acenocoumarol. ${ }^{14}$

Some prefer to continue vitamin $\mathrm{K}$ antagonists, but others switch to subcutaneous UFH or LMWH, particularly between weeks 6 and 12. The choice should be made after clearly informing the patient and her partner of the risks inherent in the different strategies. In our case the patient was shifted from tab acitrom $3 \mathrm{mg}$ to inj. enoxaparine sodium (LMWH) from 6 to 12 weeks of pregnancy. The use of warfarin throughout pregnancy provides the best maternal protection ${ }^{12,15}$ but has been associated with a high rate of fetal loss (including miscarriage, still-birth, and neonatal death), besides the risk of embryopathy. ${ }^{17}$ The strategy of administering heparin during the first trimester followed by a vitamin $\mathrm{K}$ antagonist is associated with more than double the risk of maternal thromboembolic complications or death, compared to warfarin throughout pregnancy. ${ }^{12}$ This may be the reason for mitral valve thrombosis in patient as she was switched to LMWH (inj enoxaparine ) from vitamin $\mathrm{K}$ antagonist in first trimester.

However, there is general agreement regarding treatment after the first trimester. The usual recommendation is that vitamin $\mathrm{K}$ antagonists be used, and replaced by subcutaneous or intravenous heparin at the $36^{\text {th }}$ week to avoid the risk of neonatal intracranial hemorrhage during delivery. ${ }^{14}$ The switch of anticoagulation regimens during pregnancy should be implemented in a hospital. ${ }^{14}$ If delivery starts while on OAC, cesarean delivery is indicated. ${ }^{14}$ In patients with a high risk of valve thrombosis, a planned cesarean section may be considered (keeping the time without OAC as short as possible). ${ }^{14}$

In the case of our patient, because of the daily dose requirement of $>5 \mathrm{mg}$ warfarin, which is known to be more teratogenic, acenocoumarol was substituted for warfarin. ${ }^{15,16}$ It is estimated that a mean daily dose of $5 \mathrm{mg}$ warfarin has the same anticoagulant effect (measured by INR levels) as a mean daily dose of $2 \mathrm{mg}$ acenocoumarol. ${ }^{18}$ This is the rationale for the guideline recommendation regarding the cutoff value ( $2 \mathrm{mg}$ per day) for deciding on whether to maintain acenocoumarol or to switch to heparin between weeks 6 and 12 of gestation. ${ }^{14}$ This was the reason for switching over to LMWH from 6 to 12 weeks in our patient. Nevertheless, it should be noted that there are no dose-effect studies on the teratogenic potential of acenocoumarol. Our patient had an uneventful pregnancy on a mean daily dose of $3 \mathrm{mg}$ acenocoumarol.

The incidence of thromboembolic complications in pregnancy with PHV in a large review has been reported to be $3.9 \%$ with warfarin, $9.2 \%$ with unfractionated 
heparin in the first trimester followed by warfarin and 33\% with unfractionated heparin throughout. ${ }^{12}$ With LMWH, incidence has been reported to be $3.6 \%$ with use only in the first trimester and $9 \%$ with use throughout pregnancy. ${ }^{19}$ ACC/AHA guidelines recommend warfarin continuation throughout pregnancy if dosage $<5$ mg. ${ }^{20}$ LMWH administration necessitates anti-Xa monitoring, which is not freely available in many centres. ${ }^{19,21}$

American college of cardiology/American heart association (ACC/AHA) 2006 guidelines for the management of patients with valvular heart disease for treatment of PVT recommends surgical therapy as a class IIa indication and fibrinolytic therapy as a class IIb indication. $^{5}$ Nevertheless, in the right-hand side PVT, fibrinolytic therapy is considered as the first line treatment. ${ }^{22-24}$ Usually, surgical therapy is the treatment of choice in the left-hand side PVT, especially in case of large clot burden, New York heart association (NYHA) functional class III-IV symptoms, chronic obstruction, or in cases of early postoperative obstruction. ${ }^{5,22}$ However, fibrinolysis therapy may be considered in critically ill patients with acute thrombosis if urgent surgery is not possible, or if surgery is contraindicated, or in case of small clot burden. ${ }^{5,22}$ However, in the absence of contraindications, recent reports suggested that fibrinolytic therapy be considered as first-line treatment for PVT regardless of functional class or thrombus size unless contraindications exist during pregnancy. ${ }^{25-30}$

Although pregnancy has been known as a relative contraindication for fibrinolytic therapy, this therapy has been administered in pregnant women for various indications including myocardial infarction, pulmonary embolism, and PVT. ${ }^{31}$

Our patient was of New York heart association (NYHA) functional class II and hence she was treated by fibrinolytic therapy and got good results. There are reports of PVT patients who were successfully treated with thrombolysis during pregnancy, without complications for both the mother and fetus. ${ }^{9,31-33}$ Fibrinolytic therapy was associated with $85 \%$ success rate, overall complication rate of $18 \%$, and mortality rate of $5.6 \%$ in the pregnant patients. ${ }^{9}$ Success of fibrinolytic therapy was higher in patients with aortic prostheses $(80 \%)$ than that with mitral prostheses $(65 \%) .^{23}$

In the literature, there is no consensus concerning the best fibrinolytic regimen. Several agents have been used as fibrinolytic treatment including streptokinase, urokinase, and rt-PA at different rates, which have similar efficacy. Transthoracic echocardiography is performed frequently with regard to transprosthetic pressure gradient, valve area, and lysis of thrombus. Most important of all, response to fibrinolytic therapy should be screened by TTE every 2 to 3 hours and dose of fibrinolytic agent should be kept at minimum for reducing fibrinolysis-related complications. ${ }^{34}$ If there is response to fibrinolytic therapy, it might be continued up to 72 hours..$^{9,24}$ Nevertheless, fibrinolytic therapy should be discontinued if there is no hemodynamic improvement after 24 hours and surgical treatment should be considered. ${ }^{23}$ In our case Fibrinolytic therapy was continued for 12 hours, following which clinical condition of patient improved which correlated with echocardiography evaluation as well. Fibrinolytic therapy can be considered as first-line therapy in pregnant women complicated with PVT but with NYHA functional class I-II as in our case; however, role of fibrinolytic therapy in case of NYHA functional class III-IV should be clarified in further studies.

If surgery is planned for valve replacement with or without caesarean, preoperatively, prosthetic valve status, gestational age, anticoagulants and medications should be recorded, and bridging therapy with unfractionated heparin or LMWH should be considered, which can be stopped 4-12 hours before surgery.

Intraoperative concerns depend upon the clinical status of the patient and surgical plan, whether isolated valve surgery or combined with CS. Routine monitors along with invasive arterial and CVC are desirable. Poor oxygen reserve, pulmonary congestion, full stomach and difficulty in intubation are challenges to be considered. Haemodynamic goals include maintaining an acceptable slow heartbeat, sinus rhythm, avoiding aorto-caval compression, nor-movolemia, normotension and pain relief, with an eye on avoiding exaggeration of PAH. If CS is planned, avoid opioids till delivery and minimize incision to delivery time. Risk of pulmonary oedema is high due to auto-transfusion of uterine blood after delivery. $\mathrm{PPH}$ is a major concern in this case due to heparinization; hence, oxytocin infusion should be considered (10U/h). Prostaglandins and hot mops are recommended to improve uterine tone. Because anticoagulants are started postoperatively, the risk of delayed PPH is high. Use of anti-fibrinolyics, adequate heparin reversal and avoidance of hypothermia are some of the measures that can be taken by the anesthesiologist to minimize blood loss.

Postoperatively, risk of $\mathrm{PPH}$ and thrombosis due to hypercoagulability require cautious balancing. In our case, oxytocin infusion was continued till 6 hours postoperatively, while inj enoxaparine was started 12 hours after caesarean section to prevent thrombosis; however, there are no recommended guidelines for the duration of oxytocin infusion after concomitant CS and cardiac surgery. Elective ventilation is desirable owing to preoperative PAH and pulmonary congestion.

\section{CONCLUSION}

Prosthetic valve dysfunction in pregnancy increases the risk of adverse outcomes for both mother and foetus. All women with mechanical prosthetic cardiac valves should be counseled on the various anticoagulant regimes available, with advantages and disadvantages discussed in 
detail, preferably prior to stopping contraception or planning a pregnancy.

Those with a suspicion of valve malfunction should be urgently seen by an MDTO consisting of cardiology/cardiothoracic/high-risk bstetrics/neonatology (if relevant) and anaesthetics.

Our case highlights the need to review anticoagulation in pregnancy with care. Early referral to a tertiary hospital with both obstetric and cardiac surgical services is important because of the high risk of adverse events during pregnancy in women with prosthetic heart valves. We must be well-versed with the challenges involved in PHV thrombosis and its appropriate perioperative management in these patients.

Funding: No funding sources Conflict of interest: None declared

Ethical approval: Not required

\section{REFERENCES}

1. Shah B, Sharma M, Kumar R, Brahmadathan KN, Abraham VJ, Tandon R. Rheumatic heart disease: Progress and challenges in India. Indian $\mathrm{J}$ Pediatr. 2013;80(1):77-86.

2. Van Hagen IM, Roos-Hesselink JW, Ruys TPE, Merz WM, Goland S, Gabriel H et al. ROPAC Investigators and the EURObservational Research Programme (EORP) Team. Pregnancy in women with a mechanical heart valve: data of the European Society of Cardiology Registry of Pregnancy and Cardiac Disease (ROPAC). Circulation. 2015;132:132-42.

3. D'Souza R, Ostro J, Shah PS, Silversides CK, Malinowski A, Murphy KE et al. Anticoagulation for pregnant women with mechanical heart valves: a systematic review and meta-analysis. Eur Heart J. 2017;38:1509-16.

4. Vahanian A, Baumgartner H, Bax J, Butchart E, Dion $\mathrm{R}$, Filippatos $\mathrm{G}$ et al. Guidelines on the management of valvular heart disease: The Task Force on the Management of Valvular Heart Disease of the European Society of Cardiology. Eur Heart J. 2007;28:230-68.

5. Bonow RO, Carabello BA, Kanu C, de Leon AC Jr, Faxon DP, Freed MD et al. ACC/AHA 2006 guidelines for the management of patients with valvular heart disease: a report of the American College of Cardiology/American Heart Association Task Force on Practice Guidelines. Circulation. 2006;114:e84-231.

6. Steinberg ZL, Dominguez-Islas CP, Otto CM, Stout KK, Krieger EV. Maternal and fetal outcomes of anticoagulation in pregnant women with mechanical heart valves. J Am Coll Cardiol. 2017;69:2681-91.

7. Baumgartner H, Falk V, Bax JJ, De Bonis M, Hamm C, Holm PJ et al. ESC Scientific Document Group. ESC/EACTS Guidelines for the management of valvular heart disease. Eur Heart J. 2017;38:273-80.
8. Sharouni E, Oakley CM. Outcome of pregnancy in women with valve prostheses. $\mathrm{Br}$ Heart $\mathrm{J}$. 1994;71(2):196-201.

9. Tong AT, Roudaut R, Ozkan M. Prosthetic Valve Thrombolysis-Role of Transesophageal Echocardiography (PRO-TEE) Registry Investigators. Transesophageal echocardiography improves risk assessment of thrombolysis of prosthetic valve thrombosis: results of the internationalPRO-TEE registry. J Am Coll Cardiol. 2004;43(1):77-84.

10. Ca'ceres-Lóriga FM, Pe'rez-López H, MorlansHernandez K. Thrombolysis as first choice therapy in prosthetic heart valve thrombosis. A study of 68 patients. J Thromb Thrombolysis. 2006;21(2):185-90.

11. Lengyel M. Thrombolysis should be regarded as firstline therapy for prosthetic valve thrombosis in the absence of contraindications. J Am Coll Cardiol. 2005;45(2):325.

12. Chan WS, Anand S, Ginsberg JS. Anticoagulation of pregnant women with mechanical heart valves: a systematic review of the literature. Arch Intern Med. 2000;160(2):191-6.

13. Heidemann $\mathrm{BH}, \mathrm{McCl}$ re $\mathrm{JH}$. Changes in maternal physiology during pregnancy. BJA CEPD Rev. 2003;3:65-8.

14. Regitz-Zagrosek V, Blomstrom Lundqvist C, Borghi. ESC Guidelines on the management of cardiovascular diseases during pregnancy: the Task Force on the Management of Cardiovascular Diseases during Pregnancy of the European Society of Cardiology (ESC). Eur Heart J,2011;32:3147-97.

15. Sillesen M, Hjortdal V, Vejlstrup N. Pregnancy with prosthetic valves-30 years' nationwide experience in Denmark. Eur J Cardiothorac Surg. 2011;40:448-54.

16. Cotrufo M, De Feo M, De Santo LS. Risk of warfarin during pregnancy with mechanical valve prostheses Obstet Gynecol. 2002;99:35-40.

17. Schaefer C, Hannemann D, Meister R. Vitamin K antagonists and pregnancy outcome. A multi-centre prospective study. Thromb Haemost. 2006;95:94957.

18. Van Leeuwen Y, Rosendaal FR, Van der Meer FJ. The relationship between maintenance dosages of three vitamin $\mathrm{K}$ antagonists: acenocoumarol, warfarin and phenprocoumon Thromb Res. 2008;123:225-30.

19. Abildgaard U, Sandset PM, Hammerstrøm J, Gjestvang FT, Tveit A. Management of pregnant women with mechanical heart valve prosthesis: Thromboprophylaxis with low molecular weight heparin. Thromb Res. 2009;124:262-7.

20. Nishimura RA, Otto CM, Bonow RO, Carabello BA, Erwin JP $3^{\text {rd }}$, Guyton RA et al. 2014 AHA/ACC Guideline for the management of patients with valvular heart disease: A report of the American College of Cardiology/American Heart Association Task Force on Practice Guidelines. Circulation. 2014;129:2440-92.

21. Yinon Y, Siu SC, Warshafsky C, Maxwell C, McLeod A, Colman JM et al. Use of low molecular weight 
heparin in pregnant women with mechanical heart valves. Am J Cardiol. 2009;104:1259-63.

22. Roudaut R, Lafitte S, Roudaut MF. Fibrinolysis of mechanical prosthetic valve thrombosis: a singlecenter study of 127 cases. J Am Coll Cardiol. 2003;41(4):653-8.

23. Alpert JS. Fibrinolysis of mechanical prosthetic valve thrombosis: a single-center study of 127 cases. J Am Coll Cardiol. 2003;41(4):653-60.

24. Peterffy A, Henze A, Savidge GF, Landon C, Bjork VO. Late thrombotic malfunction of the Bjork-Shiley tilting disc valve in the tricuspid position. Scand $\mathbf{J}$ Thorac Cardiovasc Surg. 1980;14(1):33-8.

25. Choi C, Midwall S, Chaille P, Conti CR. Treatment of mechanical valve thrombosis during pregnancy. Clin Cardiol. 2007;30(6):271-6.

26. Varadarajan P, Isaeff $D, P a i$ RG. Prosthetic valve thrombosis presenting as an acute embolic myocardial infarction in a pregnant patient: issues on anticoagulation regimens and thrombolytic therapy. Echocardiography. 2006;23(9):774-79.

27. Wei A, Alison J, Goldstein J, Tippett C, Coughlan PB. Prosthetic pulmonary valve thrombosis in pregnancy successfully treated with thrombolysis. Intern Med J. 2008;38(2):142-3.

28. Maegdefessel L, Issa H, Scheler C. 27-year-old pregnant woman with syncope and dyspnea after aortic alloplastic heart valve replacement 15 years ago. Internist. 2008;49(7):868-72.

29. Elkayam U, Bitar F. Valvular heart disease and pregnancy. Part II: prosthetic valves. J Am Coll Cardiol. 2005;46(3):403-10.

30. Rinaldi CA, Heppell RM, Chambers JB. Treatment of left-sided prosthetic valve thrombosis: thrombolysis or surgery? J Heart Valve Dis. 2002;11(6):839-43.

31. Leonhardt G, Gaul C, Nietsch HH. Thrombolytic therapy in pregnancy. J Thromb Thrombolysis. 2006;21(3):271-76.

32. Fleyfel M, Bourzoufi K, Huin G, Subtil D, Puech F. Recombinant tissue type plasminogen activator treatment of thrombosed mitral valve prosthesis during pregnancy. Can J Anaesth. 1997;44(7):735-8.

33. Ramamurthy S, Talwar KK, Saxena A. Prosthetic mitral valve thrombosis in pregnancy successfully treated with streptokinase. Am Heart J. 1994;127(2):446-8.

34. Ozkan M, Kaymaz C, Kirma C. Intravenous thrombolytic treatment ofmechanical prosthetic valve thrombosis:a study using serial transesophageal echocardiography. J Am Coll Cardiol. 2000;35(7):1881-9.

Cite this article as: Nahar K, Nahar N. Prosthetic mitral valve thrombosis in a known case of rheumatic heart disease at 37 weeks pregnancy: a case report. Int J Reprod Contracept Obstet Gynecol 2021;10:3254-60. 